\title{
The Success Story of Capt. Angelex A. Panes on Board the M/V SKS Tiete
}

\author{
Brian Gil S. Sarinas ${ }^{1}$ and Mark Eden G. Ellaga ${ }^{2}$ \\ ${ }^{1}$ Officer-in-Charge, Research Office and Researcher, John B. Lacson Foundation Maritime University-ArevaloSto. Niño Sur, \\ Arevalo, Iloilo City, Republic of the Philippines \\ 2. Alumnus, John B. Lacson Foundation Maritime University-Arevalo and 3rd Officer, M/V SKS Tiete
}

\begin{abstract}
Few studies have been conducted on success stories of JBLFMU-Arevalo alumni. Thus, this study aimed to determine the success story of Capt. Angelex Arevalo Panes, an alumnus of the then, John B. Lacson Colleges Foundation (Arevalo), Inc. of Batch 1995 now, John B. Lacson Foundation Maritime University-Arevalo. The story of Capt. Panes tells his family and educational background, career paths, driving force to work efficiently, hardwork, coping strategies, job encounters, edged as first Filipino captain of M/V SKS Tiete, skills as effective team leader, managerial techniques in resolving conflicts under watch, problems and solutions encountered on board, preparations for his sunset life, and his message to all aspiring seafarers. This paper gives glimpse to the life of Philippine’s modern hero-a seafarer like Capt. Angelex A. Panes and lessons to those who would become seafarers.
\end{abstract}

Key words: JBLFMU-Arevalo alumnus, seafaring, success story of seafarer.

\section{Introduction}

Seafaring is a profession that entails both risks, accidents, and responsibility [1, 2]. Few studies have been conducted on the success stories of seafarers so as to inspire other seafarers and those aspiring to be seafarers. Thus, this study aimed to determine the success story of Captain Angelex A. Panes, an alumnus of the then, John B. Lacson Colleges Foundation (Arevalo), Inc. of Batch 1995 now, John B. Lacson Foundation Maritime University-Arevalo. Specifically, it aimed to determine Capt. Panes's hard earned education, his timeline career, job encounters, and future plans when he retires.

\section{Method}

\subsection{Qualitative Research Strategy}

This study utilized the narrative type of qualitative research design. Creswell [3] defined narrative research or narratology as retelling of the experiences

Corresponding author: Brian Gil S. Sarinas, Ph.D. in Sci. Education, research fields: Maritime education and training (MET) researches and biology education. as expressed in lived and told stories of individuals.

\subsection{Instrument}

The interview schedule contained 11 questions that underwent content validity. It pertains to the narrator's family and educational background, career path timeline and job encounters where many lessons can be seen that are useful to all aspiring seafarers.

\subsection{Data Collection and Analysis}

The researcher (OIC ME Ellaga) interviewed Capt. Angelex A. Panes on board the vessel, M/V SKS Tiete, last August 2014. The transcript was immediately sent to another researcher (BG Sarinas) then it was analyzed and interpreted. Themes were generated for each question. The findings were referred to the first person narrator, Capt. A. A. Panes, for validity.

\section{Results}

3.1 Family and Educational Background and Career Path

Capt. Angelex Arevalo Panes was born in 
Kabasalan, Zamboanga del Sur, Philippines on September 15, 1975. His father, Angelino Juaniza Panes, was an electrician and his mother, Exaltacion Arevalo Panes, was a teacher. He is the eldest of the two siblings. He has a loving wife, Nestle Laine Grace Balatayo Panes and they are blessed with two children.

He took his elementary education at Kabasalan Central Elementary School from 1982 up to 1988 while his secondary education at St. Joseph School at Zamboanga City from 1988 up to 1992. In terms of his career path timeline, he started as Deck Cadet in 1995 up to 1996 on board the general cargo; Ordinary Seaman in 1996 up to 1997 on board the general cargo; Able Bodied Seaman in 1997 up to 1998 also in general cargo; Third Officer in 1999 up to 2004 aboard the OBO Carrier and General Cargo, where at this starting stage of his career, he was one of the Top 10 Passers of the PRC Board Exam for Third Mates in November of 1997; Second Officer in 2004 up to 2007 aboard the OBO Carrier; Chief Officer in 2007 up to 2012 aboard the OBO Carrier; and as Master Mariner in 2013 up to the present also in OBO Carrier. As of 2014, he has 11 years sea service and has served nine ships.

\subsection{Driving Force to Work Efficiently and Personal Motto}

Capt. Panes's believes that his distinct personality drives him to do his job and fulfills the responsibility given to him. As what he said, it is my personality which drives me to do my job and efficiently carries out any responsibility being entrusted to me on board. In terms of his personal motto, he says one must work wholeheartedly not just for the good of men but more importantly for the glory of the Lord and he will be blessed. This is evidenced by his quote as, in whatever you do work with all your heart, doing it for the Lord and not for men and you'll receive an inheritance from Him as a reward.

3.3 Hardwork, Coping Strategies, and Job Encounter Experiences

Capt. Panes started to share his hardwork when he entered college life at the then John B. Lacson Colleges Foundation (Arevalo), Inc. in 1992. He narrated: Then college days came, I decided to leave Mindanao and went to Iloilo City in order to find an engineering school where I could study my preferred course. Unfortunately, we ended up checking the John B. Lacson Colleges Foundation in Molo. I was amazed on the opportunities that I saw on the boards posted next to the guidance office which showed names of students under scholarship program from different multi-national shipping companies. So I decided to enrol for Bachelor of Science in Marine Transportation (BSMT) in John B. Lacson Arevalo and even applied for scholarship from any shipping company despite of my low grades in high school. Anyhow, school days begin and I found out that most of the students who passed the scholarship program were mostly valedictorians or salutatorians during their high school and I was too far away from the honor list compared to them.

When Capt. Panes goes to his hometown during his vacation, he used to drive their pedicab. He narrated: During my college days, I only went home twice a year during Christmas and Summer Vacation. While at home, I fixed our pedicab and embellished it with small bulbs which I took from our malfunctioning Christmas lights so that I had some illumination when passing dark streets. Every day on my vacation day, at around $1,500 H$, the sun was not so hot anymore so I used to take with me my pedicab and started moving along the town roads to earn money from passengers since it was the most economical ride in our town even nowadays. I got 2 pesos for every passenger's ride. Since December is a rainy season, I fabricated a cover for my pedicab out of scrap plastic sheets from a friend in order that my passengers would not get wet as well as myself. After 10 hours of street pedalling, I went home around $0100 \mathrm{H}$ since that was also the time when the movie goers and karaoke lovers go home. Doing this routine during Christmas and summer vacation I earned around 120 pesos everyday and by the time I went back 
to Iloilo to continue my studies, I already had my own money to pay for the ferry boat and to buy myself a pair of new pants out of my sweat and tears.

As a college student, Capt. Panes adapted to his environment and established his coping mechanisms in his studies. He said that, I studied with the same study habits as I had during my high school and after the first semester, I managed to have all my grades above $85 \%$ except on one subject which almost made me qualified to be an academic scholar. Second semester came and I didn't lose hope to become an academic scholar in order to help my parents with all the financial needs that I had. Anyhow, I always ended up every semester with one or two subjects below $85 \%$. But I said to myself, even though I am not a scholar, at least I learned something and I was able to prepare myself to be ready for an examination when I should want to apply for employment soon.

The most exciting part of this paper is that when Capt. Panes started his career as a seafarer. His experiences are so diversed from support level up to the management level. He narrated: I started sailing with my first ship on July 22, 1995 and faced a new environment which required a lot of courage and determination in order to survive. On the other hand, it was full of excitement. As the days went by, I said to myself that I had to study and learn as much as I could while onboard in order to become an officer someday. In 1997, I got my 3rd mate license and was able to use it in 1999. Life at sea is not easy especially when you start to have an officer's responsibility. But despite of the new challenges that I encountered, I continued to enhance my skills with the help of our company which provided us free training in order to enhance our competency. During my first contract as second mate, I tried to acquire as much techniques and knowledge as I could from our Chief Mate and I was supposed to leave since a Filipino Chief Mate rank is impossible in our company. However in October 2007, I received a phone call from our crewing manager telling me to join SKS Tiete as Chief Officer. I was really surprised by such huge blessing and I took the opportunity and joined SKS Tiete with just 10 weeks on and 10 weeks off contract. Unfortunately, I stayed onboard longer and made my first contract for a total of 20 weeks. But anyhow, it was also an advantage for a beginner like me since I was able to acquire more experience and challenges on the management level. Being a Chief Officer for almost five calendar years was going fine and I was lucky enough to have cooperative crew and ever supporting management team. Eventhough we had tough times often, shipboard operations were usually successful on the end. In September 2012, I was asked to go to Bergen, Norway at KGJS office as part of their assessment for promotion to Master. Various tasks were given to me and I went back home after 10 weeks with a very good news on hand-I will be a Captain on one of SKS Vessels, the first Filipino to take such post. What a great privilege it was for all Masters serving SKS Vessels where only European nationals occupy. I said to myself that we all grew up in the same environment with the SKS and knew the vessel by heart, so there is nothing to be afraid of. In February 2013, I finally took over the command of SKS Tiete. I didn't have a difficulty to start since I was the chief mate of this vessel for four years. New positions with new challenges were on hand. As they say, the start is just difficult but as you further go along, things will just fall into their places.

\subsection{Edge as the First Filipino Captain of SKS Tiete}

For Capt. Panes, there is no secret, just be yourself, do your part and be patient to wait for the right time of everything. He claimed: There is no secret. Just be yourself and do your responsibility considering always the safety of all crew, vessel, cargo and environment. Don't rush to climb the ladder of success or get easily disappointed by your failures. The best has yet to come. I just did my part, persevered and became patient.

\subsection{Skills as Effective Team Leader}

Capt. Panes believes that open and clear 
communication that is, coaching at sea are the keys to be a successful team leader. He mentioned that: To be an effective team leader, one must know how to conduct an open and clear communication with each other starting from the management level to operational and finally down to support level. Everyone has an idea and has a chance to be heard. Putting all ideas into one sound thought the team leader could then make a wise and safe decision for the good of all. An effective team leader should be a mentor too. The mentoring I did when I was still Chief Mate has contributed confidence to me now as Captain for as far as I'm concerned, I taught them well. I had taught them how to do it right and I believed on their capacity to apply what they learnt from me. The principle is proven to be effective that officers, from support to management level should teach those people who are on the support level so as when they become officers too someday, they'll also teach their successors. At sea we never stop teaching and learning. It's always a continuous process, much more for a team leader if he wants to prosper.

\subsection{Managerial Techniques in Resolving Challenges under Watch}

For Capt. Panes, it is the team's collaborative effort that can surpass challenges and difficulties under watch. As what he said, there are so many challenges that come along the way. They are often difficult to handle and each requires a unique approach to solve. I believe that working on a ship is not a one man's job. It is through our team's effort that we can say "we did it" because when all work hand-in-hand with each other, a safer and more comfortable working and living conditions at sea is attained. Moreover, we don't ignore the potential help our office staffs ashore could render so we seek help from them whenever needed.

\subsection{Problems and Solutions Encountered on Board}

Culture, personal differences, and miscommunications are the main problems on board.
This is evidenced by his statements; as the top dog, you have to accept that everyone has his own culture and attitude. By knowing a little background of someone's origin, way of life and beliefs, it is easier to communicate and work along with a crewmate on board.

On the other hand miscommunication is inevitable. You might have given the correct order but the listener executed it the other way around due to language barrier or it was not clearly stated. There are a lot of factors which contribute to failure of effective communication like tongue or semantic barriers among others. To cover up the loop hole however, it would be more prudent to let them repeat your given orders.

\subsection{Preparations for His Sunset}

Capt. Panes prepared his retirement through acquiring land properties and investing on a small business. He explained, I'm glad that I had invested on some parcel of land during my early stage of career at sea. Hopefully next year we could start to produce rubber. If materialized, it could be a good source of a simple living. My wife is also helping me to support our finances by running a mini grocery store at our place.

\subsection{Message to All Aspiring Seafarers}

The advice of Capt. Panes to all aspiring seafarers is to become world class seafarers through hardwork, study, determination, trainings, and getting advice from senior officers. Thus, he explained, nowadays there is a huge competition between seafarers not only in the Philippines but around the globe. In order for our race to have an edge from the rest we need to be "world class competitive seafarers". However to be competitive is not an easy goal to achieve for it takes a lot of experiences, years of studies, and tonnes of trainings to be earned both at sea or onshore. On board a ship you could improve yourself by learning the tasks of a person a rank higher than you so when time comes you'll be promoted you know already what to do. Furthermore, you should read the manuals in 
order to gain right theoretical knowledge and be able to operate things in the right way. While ashore, take advantage of the trainings which are provided by the company most especially if they are free. Be proactive and don't wait for other people to push you to study and learn. On the other hand when you become officers, don't be selfish to share your knowledge. This will surely help you because if you happen to work with them again, you don't need a lot of effort to deal with or make them obey your commands. When you reach the management level, listen to the opinions, suggestions and reports of your team because they serve as your extra eyes. Some of them used to go around the vessel more often and they have the best chance to see whatever non-conformities or accidents or incidents you need to know out there. Whoever you are and whatever you do in life, it's you and only you who are in charge of yourself and your career. I hope you perform best and would always choose to make a remarkable difference.

\section{Implications}

The success story of Capt. Panes is an inspiring story for all aspiring seafarers. A lot of lessons can be learned. He started his career by hard way. His faith, courage, hardwork, determination, openness, and love for learning lead him to his success or to where he is now.

It cannot be denied that seafaring profession is not an easy profession-danger and risks are always lurking but like him any seafarer could thrive if he chooses to make a difference. Furthermore, Capt. Panes urges all seafarers and aspirants to be world class competitive seafarers and this could be achieved by attributing positive attitude, exploring all avenues to learn ashore, going the extra mile to earn valuable experiences at sea and by proving the worth of prolific sea ambassadors.

\section{References}

[1] Jensen, O. C. 2009. "Collaborative, Cross-National Studies on Health and Safety in Seafaring for Evidence-Based Maritime Policy and Regulations.”International Maritime Health 60 (1-2): 10-3.

[2] Oldenburg, M., Baur, X., and Schlaich, C. 2010. "Occupational Risks and Challenges of Seafaring.” Journal of Occupational Health 52: 249-56.

[3] Creswell, J. W. 2007. Qualitative Inquiry and Research Design Choosing among Five Approaches. 2nd ed. USA: Sage Publications, Inc. 